\title{
8. The future of the global order
}

\section{THE PROBLEM OF GLOBAL ORDER}

Most members of my generation grew up with a simple understanding of the character of the prevailing global order. We assumed, without stopping to examine this assumption critically, that we live in an international society or, in other words, a society in which the members are actors that meet the standards for recognition as states and that states are endowed with sovereignty in the sense that they have full authority over their internal affairs and are not subject to external or superordinate standards to which they have not given their explicit consent. International society is, as Hedley Bull and others have observed, an anarchical society featuring a variety of social institutions but lacking anything resembling a central government capable of exercising authority over the member states (Bull 1977). Of course, we were aware that the provisions of Chapter VII of the United Nations Charter accord formal authority to the UN Security Council to take forceful steps to address "threats to the peace, breaches of the peace, and acts of aggression" (United Nations 1945). But we recognized the difficulties in making a transition from paper to practice regarding the implementation of these provisions, particularly under the conditions prevailing following the onset of the Cold War and the resultant prospect of vetoes stymieing action on the part of the council in specific situations. And we understood the provisions of Article 2(7) of the Charter as constituting a general reaffirmation of the sovereignty of member states in other respects.

For the most part, we also took it for granted that the members of international society are nation states in the sense that they reflect a general congruence between political and cultural boundaries or, in any case, that the ideal of the nation state constitutes a kind of gold standard toward which international society is destined to evolve over the course of time. Under the circumstances, those of us interested in what we now often refer to as global governance studied international economics, international law, international politics, and international political economy. Grouped together under the heading of international relations, we had no trouble accepting the idea that this field of study provided the basis for establishing a distinct program or even a separate department within institutions of higher education and for defining the scope 
of leading journals in the field. All in all, we thought we knew what we were talking about in tackling issues pertaining to the future of the global order.

As it turns out, however, this simple understanding provides a remarkably narrow lens on issues relating to global order. There is nothing timeless or unchangeable about the character of the global order enshrined in these assumptions. The idea of a society of sovereign states came into focus initially in Europe during the 17th century in the context of an effort to resolve intractable disagreements about the nature of political authority that had triggered violent clashes culminating in the destructive Thirty Years War and that came to an end with the Treaty of Westphalia in 1648 (Wedgwood 2005). But there has always been a sizable gap between the ideal and the actual with regard to international society, and there is no sign that this gap has narrowed in recent times. Although membership in international society has grown dramatically, the capacity of many states to exercise sovereignty both internally and externally is doubtful at best. In many parts of the world, powerful outsiders regularly intervene in the affairs of nominally sovereign states. Current developments, especially those associated with the onset of the cyber age, are raising persistent questions about the extent to which individual states can control their own affairs, much less engage effectively in interactions with others. What is at stake here is not only our understanding of the character of the global order prevailing today, but also our expectations and preferences regarding the institutional dimensions of the global order of the future.

In this concluding chapter, I address this theme in several stages. The next section goes into some detail regarding the nature and magnitude of the gap between the ideal and the actual with regard to the idea that international society is a society of sovereign states. It demonstrates that reality has never conformed closely to this ideal and that the gap has not narrowed over time. This sets the stage for three parallel sections dealing with what I call change agents in the realm of global order: the spread of globalization, the rise of nonstate actors, and the onset of the cyber age. While this assessment does not lead to the conclusion that the states system is on the verge of collapse, it does provide a strong case for the proposition that fundamental change in the character of the global order is possible during the coming decades. Needless to say, none of us is in a position to make specific predictions regarding the character of the global order of the future. But it is not premature to initiate a focused examination of major pathways in this realm and the destinations toward which these pathways may lead over the course of time. I take up this topic in the final section of the chapter.

Before embarking on this journey, let me emphasize the observation that this analysis deals fundamentally with matters relating to the nature and influence of social institutions. The constitutive foundation of international society is a set of legal and political institutions. While these institutions may be deeply 
embedded both in day-to-day practices and in the minds of those who think about world affairs, they are not facts of life we must accept as permanent arrangements. What is at stake, then, is the future of the institutions that serve to define international society as a society of states and perhaps as a society of nation states. Will these institutions endure, more or less, in their current form? Are there forces at work likely to produce fundamental, even transformative, changes in this realm? If so, is there anything useful we can say at this stage about the character of the social institutions that will arise to define the basic character of the global order of the future?

\section{THE GAP BETWEEN THE IDEAL AND THE ACTUAL}

The vision of a society composed of sovereign states has never provided an accurate description of reality, even in Europe, where much of the thinking underlying this idea originated. The United Kingdom, which brought together England and Wales with Scotland early in the 18th century, expanded at the beginning of the 19th century with the addition of Ireland but contracted in the 20 th century with the recognition of Ireland as an independent state. Germany and Italy became unified states only in the second half of the 19th century. In the aftermath of World War II, the Cold War divided Germany into the separate states of East Germany and West Germany. Germany achieved reunification in 1990, but within boundaries that differ significantly from those of pre-war Germany. Norway did not become an independent state until early in the 20th century. The Baltic states - Estonia, Latvia, and Lithuania - emerged as independent states in the aftermath of World War I, disappeared into the Soviet Union in 1939, and reemerged as independent states with the breakup of the Soviet Union at the end of 1991. The Austro-Hungarian Empire, Prussia, and Russia partitioned Poland among themselves on several occasions during the 18th century. The Soviet Union absorbed Poland into the Soviet Bloc following World War II, before the country regained full sovereignty following the breakup of the Soviet Union.

What is more, much of the modern history of Europe has featured interactions among empires rather than states. The Hapsburg Empire, centered on today's Austria, encompassed Hungary, Czechoslovakia, and a sizable swath of the rest of eastern Europe until its collapse at the end of World War I. Southeastern Europe, a longstanding battleground between the Austro-Hungarian Empire and the Ottoman Empire prior to the collapse of both these empires at the end of World War I, became a multinational state with the establishment of Yugoslavia in the aftermath of World War I. But the region split apart into six successor states during the 1990s. The Soviet Union - formally the Union of Soviet Socialist Republics - joined together a multiplicity of distinct republics 
encompassing separate nations following World War I and exercised effective control over most of eastern Europe in the period following World War II. When the USSR collapsed at the end of 1991, it resulted in the (re)establishment of 14 sovereign states in addition to Russia itself.

The leading European states - the United Kingdom, France, Spain, and to a lesser extent the Netherlands, Belgium, Portugal, Italy, and Germany created overseas empires or colonial systems through which they exercised political and economic control over a large proportion of the rest of the world until the final decades of the 20th century. The United Kingdom and France dominated North America; Spain and Portugal dominated South America; the United Kingdom, France, Portugal, and Belgium dominated Africa; and the United Kingdom controlled India, a sizable part of Southeast Asia, Australia, and New Zealand. Australia, Canada, New Zealand, and South Africa achieved political autonomy in the later part of the 19th century and the early part of the 20th century. But they remained members of the British Commonwealth; several of them recognize the British king or queen as their official head of state to this day. France and the Netherlands exercised control over the rest of Southeast Asia and what is now Indonesia. In conjunction with its rapid modernization in the later decades of the 19th century, Japan joined the ranks of colonial powers, controlling Korea and Taiwan during the first half of the 20th century.

The United States became a sovereign state toward the end of the 18th century. But it did not achieve its current form until well into the 19th century through a series of purchases, conquests, and forceful expropriations of territory belonging to various groups of Native Americans. It continued to expand with the addition of Alaska and Hawaii as states during the middle of the 20th century. Canada, the other major state in North America, did not assume its current form until well into the 20th century. The Province of Newfoundland and Labrador did not join the federation until 1949. Most of the states of South America broke away from the Spanish and Portuguese empires to become independent states during the first half of the 19th century.

Even so, the United Nations had only 51 members at the time of its establishment in 1945. It now has 193 members. This explosion in the membership of international society is attributable largely to the process of decolonization starting in the 1940s and picking up steam in the 1960s and 1970s. Iceland achieved independence from Denmark in 1944. The Philippines became an independent state in 1946. Several states in the Middle East, which had been British or French Mandates under the League of Nations, became independent in the aftermath of World War II. Israel achieved statehood in 1948. British rule over the Indian subcontinent came to an end in 1947. But the subcontinent immediately broke into the independent states of India and Pakistan. Pakistan in turn separated into Pakistan (the former West Pakistan) and Bangladesh (the 
former East Pakistan) in 1971. The flow of new members into international society picked up speed with the end of colonial rule in Africa during the 1960s and 1970s. Today, Africa has a total of 54 states recognized formally as members of international society. There are as well several dozen small island states, mostly located in the Caribbean and the South Pacific, that achieved independence as a consequence of the process of decolonization during the final decades of the 20th century. The breakup of the Soviet Union and Yugoslavia during the 1990s added more than 20 additional sovereign states to the membership of international society.

During the 1950s, the process Ernst Haas described as "the uniting of Europe" got under way. France, Germany, Italy, and the three Benelux states established the European Coal and Steel Community in the 1951 Treaty of Paris (Haas 1958). Thus began a sequence of events that has led over time to the development of the European Union, expanding to include 28 members (reduced to 27 with the departure of the United Kingdom in 2020) and taking on authority in a variety of functional domains, including banking, agriculture, fisheries, and research. While few regard the European Union as an emergent superstate that will achieve legal and political dominance over its members in due course, the European Union represents an important innovation with regard to global order. Of particular interest is the fact that it has developed a system of law and administrative practices that are not rooted in the legal principles and political practices that form the bedrock of the states system.

Beyond this, it is worth noting that significant chunks of territory along with their human residents have changed hands from time to time between members of international society as a result of annexation, conquest, or purchase. The provinces of Alsace and Lorraine have changed hands between France and Germany on several occasions as a consequence of the outcomes of wars. Britain, France, and Germany established de facto control over areas on the Chinese mainland during the early decades of the 20th century through the creation of what became known as concessions. Germany annexed Austria in 1938 and large parts of Czechoslovakia in 1939. Texas declared independence from Mexico in 1835, subsequently becoming a state in the United States in 1846. The United States purchased Alaska from Russia in 1867 and annexed the Hawaiian Islands in 1898. Japan took control of a large swath of northeastern China in the 1930s, only to lose it again at the close of World War II. More recently, China asserted control over Tibet in the 1950s, the United Kingdom relinquished Hong Kong to China in 1997, and Russia annexed Crimea, taking the region forcibly from Ukraine in 2014. Whatever the legitimacy of these territorial realignments, they constitute a significant feature of the shifting character of international society.

Whether or not it is reasonable to describe the members of international society today as nation states is a separate question. We often take it for 
granted that established states like France, Germany, and the United Kingdom are nation states. But even here there are major complications. Many German-speaking people, including residents of other German-speaking states like Austria, live outside Germany, and Germany itself now has between 4 and 7 million residents of Turkish origin. The United Kingdom has millions of immigrants coming from various parts of the former British Empire. Today, there are growing questions regarding the extent to which the English and the Scots form separate nations rather than a single homogeneous nation. In many other cases, there is little or no basis for treating states as nation states. In India, there is a deep division between the majority Hindu population and the minority Muslim population. Many African states are multinational due to the vagaries of colonial administration during the era prior to the achievement of independence. In some cases (e.g., Nigeria, Rwanda), this situation has triggered violent civil wars or prolonged civil strife. Many of the states of Southeast Asia, including Indonesia, Malaysia, and Singapore, encompass large numbers of people of Chinese origin who retain their own distinctive culture. Even Israel, which has a constitution containing provisions designating it a Jewish state, has an Arab minority constituting more than $20 \%$ of the population.

Then, there are states like the United States that are often regarded as nation states by virtue of the operation of what is commonly described as the melting pot. The basic idea is that millions of people who came to the country as immigrants from places like Ireland, Italy, Scandinavia, and various parts of eastern Europe would and should assimilate as quickly as possible, forming a distinct nation in the process. To a degree, this line of thinking seems reasonable. But it does not fit comfortably in cases like the blacks brought to the United States as slaves, the Chinese who came to the country as a source of cheap or indentured labor, or many Latinx communities that remain quite distinct from the mainstream in America. Similar observations apply to states like Argentina and Australia that are clearly multiethnic even though there may be some basis for debating whether it makes sense to describe them as multinational.

What this brief survey makes clear is both that the gap between the ideal and the actual is wide with regard to the idea of international society as a society of sovereign states and that a large fraction of the current membership are states of recent origin. Although formal membership in this society has grown to almost 200, many member states struggle to live up to the defining features of statehood with regard both to internal sovereignty and to external sovereignty. Various forms of interference in the affairs of member states constitute the norm rather than the exception. Many small island states are micro-states that may literally disappear as a consequence of the impacts of climate change. In any case, it is a stretch to regard many members of international society as nation states. Nevertheless, the idea that international society is fundamentally 
a society whose members are sovereign nation states has a powerful and lasting grip on the thinking of many students of international relations as well as most members of the general public. This grip is reinforced in the basic tenets of international law governing the terms of membership in international society, which originated in the work of prominent European thinkers during the 17 th and 18 th centuries. No doubt, the influence of this paradigm lives on, at least in part, not only because it is inscribed in the administrative practices of existing states but also because the idea of a society of nation states reflects a normative preference that is embedded in the outlook of many who pay attention to international relations. Still, there is no indication that the gap between the ideal and the actual regarding the character of the prevailing global order is narrowing, and there is no basis for limiting our thinking about the future of the global order to a continuing effort to shoehorn reality into the paradigm of an international society (Morris 2011).

Not everyone shares the view that we should treat the paradigm of international society as a fact of life and get on with the business of adapting reality to this vision to the maximum extent possible. Over the last 50 years, several strands of thought have emerged that seek to address what Stanley Hoffmann famously described in the 1960 s as the question of whether the state is obstinate or obsolete (Hoffmann 1966). Each of these strands highlights a force or cluster of forces that may be eroding the role of the state as the dominant actor in world affairs. Treating these forces as change agents, I discuss the principal observations regarding the future of the global order that have emerged from these strands of thought in the next three sections under the headings of the spread of globalization, the rise of nonstate actors, and the onset of the cyber age. The result is a roughly chronological profile of the evolution of the debate about the role of the state in the sense that it directs attention to a series of ideas that have emerged and become influential sequentially over the course of a number of decades. Nevertheless, there is no reason to regard these strands of thought as separate or unrelated. It makes more sense to treat the impacts of these change agents as cumulative as we seek to organize our thinking about future directions in the character of the global order.

\section{CHANGE AGENTS 1: THE SPREAD OF GLOBALIZATION}

A helpful point of departure is a focus on the rise of globalization that became a prominent area of interest to students of international relations during the 1970s and 1980s. The term globalization points to a suite of developments that many see as having important consequences for the future of international society (Friedman 2005). Corporations grew larger, frequently becoming multinational or transnational corporations (MNCs or TNCs) with extensive 
networks involving operations in many countries. The largest MNCs or TNCs increased in size until they generated annual streams of revenues larger than the GDPs of the majority of the members of international society. A particularly notable feature of this economic globalization was the development of longer and longer supply chains, featuring the extraction of raw materials in countries located in Africa or South America, the assembly of finished products in China or the countries of Southeast Asia, and the shipment of goods at various stages of the production process from one place to another by sea. This gave rise to the observation that the scale of commercial shipping has grown to the point where it accounts for $90 \%$ of everything (George 2013). By the early years of the 21 st century, the world's producers and consumers were operating in a tightly coupled global system. Although some are now disillusioned with this system, experience suggests that decoupling is easier said than done.

In addition to the resultant growth in the magnitude of international trade relative to the size of the global economy, comparable developments were under way with regard to investment and financial services. Foreign direct investment (FDI) grew rapidly, fueled by the investment decisions of MNCs and TNCs and amplified by the initiatives of international organizations like the World Bank and state-controlled organizations like the China Development Bank. Associated with this development was the growth of banking services with a global reach. For example, Iceland, with a population of under 350,000, became the base of operations for four banks operating on a global scale. Among other things, this allowed large corporations and wealthy individuals to shift both money and legal residences from place to place to take advantage of favorable tax rates and to minimize their exposure to the financial regulations of individual countries.

While observers have paid particular attention to these economic developments, globalization is prominent also in other domains, including popular culture, tourism, environmental concerns, and public health. Both fueled by and fueling the spread of English as a second language, Western films and popular culture have achieved a global reach. The flow of people moving across national boundaries for recreational as opposed to business purposes has increased steadily. Largescale environmental concerns, like climate change, the loss of biological diversity, long-range transboundary air pollution, and the spread of plastic debris constitute what Kofi Annan, UN Secretary-General from 1997 to 2006, called "problems without passports" (Annan 2009). As a growing incidence of public health concerns culminating in the recent Covid-19 pandemic has made abundantly clear, disease vectors are global; the public authorities of states have only the most rudimentary capacity to prevent infectious diseases from entering their jurisdictions (Snowden 2019).

States have played a prominent role along with private and quasi-private actors in taking steps to promote globalization. States have entered into both 
global agreements, like the 1948 General Agreement on Tariffs and Trade and the 1994 Marrakech Agreement creating the World Trade Organization, and regional agreements, like the 1957 Treaty of Rome and the 1992 North American Free Trade Agreement, designed to promote the growth of international trade. They have also negotiated hundreds of bilateral investment treaties to eliminate or alleviate difficulties that otherwise might impede the flow of foreign direct investment. Similar observations are in order regarding other forms of globalization. States have taken a variety of stops to facilitate visa-free travel, to initiate joint responses to largescale environmental issues, and to launch collaborative efforts to reduce poverty and promote public health through initiatives like the UN's Millennium Development Goals (2000-2015) and Sustainable Development Goals (2015-2030).

In some cases, the efforts of states - directly or indirectly - have figured prominently in the rise of globalization. Both Chinese state-owned enterprises (SOEs) and the China Development Bank are prominent players in the realm of foreign direct investment. China's Belt and Road Initiative (BRI), promoted by President Xi Jinping since 2013, is shaping up as the largest programmatic effort to enhance foreign direct investment and overall economic integration in history. Both Korea and Japan, which have played prominent roles in the globalization process, have domestic systems featuring extremely close relations between large corporations and government agencies. It is not surprising, under the circumstances, that the field of international political economy has emerged as a prominent area of specialization among analysts who have produced some of the most rigorous and influential studies in the overarching field of international relations during recent decades (Keohane 1984).

What are the implications of the rise of globalization for the future of the global order? The core argument in this connection focuses on the role of interdependence and especially what Robert Keohane and Joseph Nye have described as complex interdependence (Keohane and Nye 1977). Globalization, on this account, leads to the growth of interdependence among the members of international society. As the process continues, globalization gives rise to an increasingly complex network of relationships that circumscribe the freedom of action of individual states in a variety of ways. The result is a situation in which states find it increasingly difficult to exercise sovereignty effectively, both externally in their dealings with other states and internally in their dealings with their own subjects.

With regard to external sovereignty, the critical argument is that globalization both increases the importance of soft power in contrast to hard power and drives up the costs of engaging in geopolitical initiatives featuring the deployment or use of military force (Nye 2005). Actors preoccupied with the promotion of trade and investment, the flow of people, and the challenges of addressing largescale environmental or public health concerns will have little 
interest in the traditional concerns of power politics. From their perspective, conventional efforts to improve the rankings of individual states in the realm of power politics are of little interest. Even more to the point, exercises in power politics seem increasingly costly to the extent that they jeopardize or even undermine the benefits accruing from the growth of international trade, the movement of people across national boundaries, and the mounting of cooperative efforts to address environmental and public health challenges. In effect, the gains from cooperation loom larger and larger relative to any benefits to be derived from exercises in power politics, and the costs of conflict increase to the extent that they undermine cooperative relationships. As a result, national policymakers will discover that globalization has the effect of diminishing their freedom of action.

Globalization, on this account, also imposes limits on internal sovereignty. Under conditions of complex interdependence, MNCs and TNCs have the capacity to engage in autonomous activities that are difficult for governments to control. The growth of debt owed to foreign investors limits the ability of governments to control their own economic systems. The spread of popular culture on a global basis makes it harder and harder for governments to cut off their citizens from foreign influences in order to control their behavior. The spread of infectious diseases like Covid-19 and the intensification of global environmental concerns like climate change give rise to crises within countries that upend the plans of governments and divert their attention from other priorities. Under the circumstances, globalization not only limits the appeal of efforts to exercise hard power at the international level; it also makes it progressively more difficult for governments to pursue coherent political programs within their own jurisdictions.

These developments clearly played an influential role in stimulating the rise of new thinking in the field of international relations. Perhaps the most important development falls under the heading of what is generally called neoliberal institutionalism (Hasenclever et al. 1997). The key observation here, as Robert Keohane put it in his influential study entitled After Hegemony, is that states can and do develop a variety of international institutions to pursue common or compatible objectives without the engagement of a dominant power to impose order on the members of international society (Keohane 1984). Unlike traditional studies of international organizations inspired by the perspectives of public administration, the resultant flow of research emphasized the central role of institutions in contrast to organizations and directed attention to the creation of international regimes, initially in the realm of economic relations (e.g., the international trade system) but increasingly in other realms like arrangements created to address a variety of environmental issues. As the institutionalists put it, it became relevant to think about "governance without government" 
in international society and in due course to ask a range of questions regarding the evolution of global governance (Rosenau and Czempiel 1992).

There is no question that the developments under consideration here raised importance questions about simple conceptions of international society as a society of sovereign states. In a globalized world, states have good reasons to limit their actions, and a variety of other actors, including MNCs, TNCs, and major banks, are able to operate with considerable autonomy. Still, it is important not to exaggerate the importance of these developments. The basic institutions of global order, from the Charter of the United Nations to the Marrakech Agreement and the Framework Convention on Climate Change are all created under the terms of legally binding international treaties or conventions. Membership in major international organizations, like the United Nations, the International Trade Organization, or the World Health Organization, is reserved for actors that are recognized as states. Even major corporations are legally incorporated under the laws of states, though it may be increasingly difficult for individual states to exercise effective control over corporations that are able to shift their legal bases of operations to jurisdictions that offer more favorable regulatory environments. In effect, the basic institutional structure of the states system is deeply embedded in day-to-day practices, despite the fact that the resultant arrangements often prove ineffective in dealing with contemporary needs for governance.

As a number of analysts have noted, globalization as measured by factors like the scale of international trade and the magnitude of foreign direct investment, had reached a remarkably high level in the decades prior to World War I. Many believed that the resultant interdependence would make war, at least on a large scale, obsolete. Yet, escalating tensions, fueled by developments like the naval arms race between Germany and Great Britain, led to the outbreak of a devastating war following what seemed like a relatively minor crisis during the summer of 1914. Similarly, we are witnessing today a movement toward economic decoupling on the part of major actors like the United States and China, despite the power of global supply chains and the influence of an extraordinary array of global communications systems. This is not to deny the impacts of globalization. The effectiveness of both American unilateralism and Chinese efforts to erect the Great Firewall blocking the access of its citizens to outside influences are open to serious question. Nevertheless, it would be a mistake to fall into the trap of thinking that the continuing course of globalization will make the state obsolete, opening the way for the rise of some new form of global order in which states are no longer the principal actors. 

ACTORS

During the 1990s and 2000s, interest turned to the rise of a wide range of nonstate actors as a development with the potential to catalyze the growth of a new form of social order at the global level in which membership is no longer limited to actors that qualify as states and that are recognized as such by other members of international society. Of course, multinational and transnational corporations are nonstate actors. But the rising interest in nonstate actors at the global level followed the practice of those who think about civil society within states as a layer of social organization below the level of the state and above the level of the individual or family, which encompasses a wide range of organizations other than corporations and other familiar economic actors. On this account, the universe of nonstate actors is broad, ranging from artistic and scientific groups to organizations concerned with the promotion of public health and the treatment of environmental problems (Dingwerth 2007; Pattberg 2007).

In thinking about ways in which the activities of nonstate actors may influence the character of the global order, it is helpful to differentiate among types of actors in terms of their contributions to addressing needs for governance. Many nonstate actors (e.g., Greenpeace, the Natural Resources Defense Council, WWF) work primarily within the institutional nexus of international society (Wapner 1996). They seek to influence the actions states take as members of intergovernmental arrangements or the policies individual states adopt that have international consequences. But there are other nonstate actors that are assuming roles in responding to needs for governance in their own right rather than seeking to influence the behavior of states. At least four clusters of cases are worth differentiating in thinking about the resultant contributions of nonstate actors.

First and perhaps foremost, there are nonstate actors that operate as freestanding agents and play regulatory roles not authorized by states. Prominent examples include the Forest Stewardship Council (FSC) and the Marine Stewardship Council (MSC). These bodies have established systems to assess the sustainability of the practices of harvesters of forest and marine products, to certify those that meet the standards they have adopted regarding sustainability, and to monitor the compliance of those they certify with the relevant standards over time. While there are legitimate questions regarding the effectiveness of these efforts, there is no doubt that they reflect an approach to regulation that differs from conventional approaches relying on intergovernmental bodies. Another well-known case is the International Association of Antarctic Tour Operators (IAATO). This nonstate actor regulates the activities of tour 
operators in the interests of ensuring safety and minimizing the environmental impacts associated with tourist visits to Antarctica and the islands of the Southern Ocean. It constitutes a form of self-regulation motivated at least in part by a desire on the part of tour operators to avoid the creation of a conventional intergovernmental arrangement to deal with the relevant concerns.

A second cluster of nonstate actors includes those that play distinct roles along with intergovernmental bodies in the development and implementation of regulatory arrangements. Consider, as prominent examples, the roles the International Association of Classification Societies (IACS) and major insurers play in regimes dealing with maritime commerce. The regulations are set, for the most part, by the International Maritime Organization (IMO) or in the provisions of treaties negotiated under the auspices of the IMO. But the IMO, which is an intergovernmental body, has little capacity to handle the implementation of the resultant regulations or to administer them on a day-to-day basis. This is where IACS and the insurance industry enter the picture. These actors are able to certify whether ships meet regulatory standards (e.g., those dealing with double-hull construction for tankers or the possession of a valid Polar Certificate for ships operating in polar waters) and to ensure compliance by providing insurance to or withholding it from the owners and operators of the vessels. The result is a regulatory system that takes the form of a collaboration between intergovernmental bodies and nonstate actors in which the nonstate actors are autonomous entities capable of making contributions that extend beyond the capacity of intergovernmental bodies like the IMO.

The third cluster includes nonstate actors that engage in programmatic activities that are independent of the oversight of intergovernmental bodies and that generally extend beyond the reach of states. A particularly prominent examples involves the role of the Rockefeller Foundation in initiating and funding what is generally known as the Green Revolution, a concerted effort taking place during the 1950s and 1960s and focusing on increasing food production through the development of high-yielding varieties of wheat and rice and the use of chemical fertilizers (Mann 2019). While the Green Revolution has been criticized from a variety of perspectives, there is no doubt that this nonstate initiative has made a significant difference in expanding the production of food crops in a number of developing countries. More recently, the Bill \& Melinda Gates Foundation, operating both independently and in cooperation with intergovernmental bodies, has emerged as an influential player in the realm of public health (Snowden 2019). The foundation has played a leading role in the Global Fund to Fight AIDS, Tuberculosis, and Malaria; it has devoted substantial resources to the campaign to eradicate polio. Some critics have questioned the choice of priorities by nonstate actors like the Gates Foundation. But there is no doubt that such actors have made a difference at the global level with regard to developments in the realm of public health. 
Finally, there are cases featuring public/private partnerships in which intergovernmental bodies and nonstate actors join forces as equal partners in efforts to address societal issues (Andonova 2017). A striking example is GAVI, the Vaccine Alliance that joins government agencies, intergovernmental bodies (e.g., WHO, UNICEF), industries, research agencies, foundations, and other private philanthropists to promote the development and administration of vaccines for a variety of diseases (Andresen and Iguchi 2017). Given the political sensitivities surrounding immunization, it is not surprising that some of GAVI's initiatives have been controversial. The performance of actors like GAVI in the distribution and administration of vaccines for Covid-19 will constitute an important test for such partnerships. More generally, the idea of turning to public/private partnerships has been promoted vigorously in settings like the 2002 World Summit on Sustainable Development. The available evidence suggests that many efforts of this sort fail to achieve their goals. Yet there is also evidence that public/private partnerships can make a difference under some circumstances, a finding that suggests that it will be important in the coming decades to pay careful attention to the significance of this development for the future of the global order (Andonova 2017).

Some analysts, influenced by the extensive literature on the role of civil society in domestic systems, have suggested that the activities of these several clusters of nonstate actors are indicative of the "rise of transnational civil society" or the emergence of a layer of social organization at the international level that resembles what we generally think of as civil society at the domestic level (Florini 2000; Kaldor 2003; Keane 2003). Although this is an interesting way to think about recent developments, it is not clear that it helps us to make sense out of what is happening at the global level. In the mainstream literature, organizations belonging to civil society are generally seen as operating below the state but above the level of the individual or individual family unit. Much of this literature deals with the role a robust civil society is thought to play in protecting domestic systems from the threats posed by authoritarian leaders who seek to undermine civil society in order to exercise direct control over the lives of individuals. This accounts for the influence of work by analysts like Robert Putnam who have raised searching questions about the decline of civil society in the United States (Putnam 2001).

How do recent developments at the global level map onto this line of thinking? There is no overarching state in international society. Far from worrying about authoritarian leaders capturing the apparatus of the state at the international level, we are concerned with the question of whether intergovernmental mechanisms can operate effectively enough at this level to handle routine needs for governance. Conversely, it is doubtful whether it makes sense to think of nonstate actors operating above the level of states treated as the individual members of international society. As the preceding account makes 
clear, nonstate actors are capable of playing a variety of roles that are not dependent on the approval or support of states. But they are not bodies that join together the individual members of international society to pursue a variety of interests that are not of any direct concern to some sort of world government.

Is there an alternative way to think about the rise of nonstate actors and what this development means for the future of the global order? No one expects that the state will wither away to be replaced by some assemblage of nonstate actors as the basic units of some successor to international society. The social institutions that constitute the foundation of international society are too deeply embedded in contemporary practices for any such development to occur during the near future. Yet it is also the case that nonstate actors are finding a variety of ways to escape the superordinate position of the state, operating as autonomous actors playing significant roles on a global scale. The result may be the rise of a social order that differs from international society by according membership to more than one type of actor. Whether or not such an arrangement would prove transitional in the sense of catalyzing a shift from international society to some alternative form of global order is impossible to foresee at this stage. Still, the prospect that the future may feature a global order including two or more types of actors operating on a basis of equality is an important observation. I will come back to this idea in the final substantive section of this chapter.

\section{CHANGE AGENTS 3: THE ONSET OF THE CYBER AGE}

A third change agent emerging over the last several decades but becoming a focus of attention among students of world affairs largely during the $2010 \mathrm{~s}$ centers on a stream of innovations in digital technology leading to the onset of the cyber age (Young, Yang, and Guttman 2020). Of course, technological innovation has been a major driver of societal evolution throughout human history, accelerating with the start of what is often called the First Industrial Revolution in the later decades of the 18th century (see also Chapter 7). What makes the cyber age distinctive is the development of digital technologies that make it possible to engage in many activities virtually rather than physically and give rise to a growing range of interactions between virtual reality and material (biophysical and socioeconomic) reality (DeNardis 2020). Today, the activities of many actors not only highlight virtual relationships; some actors operate largely in cyberspace rather than in material or physical space. The result is a world in which new types of actors have become influential and existing actors must learn how to use digital technologies and pursue their goals in cyberspace. There is no sign that the flood of technological innovations underlying this development is slacking off. 
With regard to the future of the global order, what makes this development profoundly important is the growth of virtual reality alongside material reality. States, treated as the members of international society, are territorial entities with well-defined boundaries that enclose spaces identifiable in geographical terms (Opello and Rosow 2004). It is true that states have succeeded in expanding the scope of their jurisdiction in spatial terms in modern times. Thus, states now exercise jurisdiction over Exclusive Economic Zones encompassing marine areas stretching out 200 nautical miles from their coastlines and over the airspace above their territories. Nevertheless, the social institutions that define the character of international society are framed in territorial terms. States have sovereign authority over activities occurring within their boundaries; they engage in interactions with other states on the basis of the principles and practices of international law. The high seas and outer space are international spaces that fall outside the jurisdiction of the individual members of international society. But they are subject to rules agreed to by the members of international society in the form of legally binding agreements like the 1982 UN Convention on the Law of the Sea.

The onset of the cyber age, by contrast, has triggered the creation of a variety of actors that are not organized as territorial entities and that do not exercise jurisdiction over any spaces identifiable in material terms. Some of these actors are single individuals who are able to engage in extensive virtual relationships with others and who can initiate disruptive interventions in the activities of government agencies and private corporations through actions that are difficult to track to their sources. In other cases, these actors are organizations, sometimes large organizations like Google or Facebook, that do have material bases of operation even though their activities largely take the form of transmitting data through virtual channels. But they are not deeply rooted in spatial terms. It would be relatively easy for such actors to shift their bases of operations from one location to another to escape or circumvent the regulatory authority of government agencies. The result is that we now operate on a global scale in a world populated with a mix of actors, some of which are conventional actors located within spatially defined boundaries and producing goods in material facilities, while others are virtual actors operating largely in cyberspace.

Needless to say, states can and do make use of digital technologies both to pursue their own interests in their dealings with others and to implement their policies domestically (Kaplan 2016; Kello 2017; Klimburg 2017; Segal 2017; Perlroth 2020). The Stuxnet episode in which the US (probably with the collaboration of Israel) made use of offensive cyber operations to disrupt Iranian uranium-enrichment centrifuges is a particularly prominent example of the deployment of digital technologies in the pursuit of national interests. But the deployment of weapons systems that make use of digital technology in one 
form or another is now routine in a variety of applications. Examples include the use of drones to guide weapons to selected targets from remote control centers, the deployment of unmanned aircraft guided remotely, and reliance on robots that are subject to remote guidance to defuse bombs and other explosive devices and to clear minefields. More developments along these lines are in store, especially as advances in artificial intelligence increase options for deploying unmanned weapons that are capable of learning as they go along and adjusting their actions to maximize their effectiveness in specific situations.

States also make use of digital technologies in pursuing domestic objectives. A particularly striking example is the development by the government of China of what has become known as the Great Firewall, a complex of digital systems intended to limit the access of Chinese citizens to information approved by the state and to enhance the capacity of the state to monitor and control the activities of citizens (Klimburg 2017). This firewall allows censors to prohibit access to information deemed inappropriate for public consumption and to take down materials quickly that are not caught by censors before they are posted on the internet. New developments in the realm of digital technology, such as sophisticated systems allowing for facial recognition, are enhancing the capability of the state to monitor the activities of individual citizens on a day-to-day basis. While precise figures are unavailable, most analysts believe that China's investment in the Great Firewall equals or exceeds the size of its defense budget.

Still, it is important to recognize the limitations associated with these uses of digital technologies on the part of states pursuing their own interests. Military uses of digital technology may have the effect of undermining the sovereignty of even the most powerful states. The reason the Stuxnet episode has attracted so much attention is that it points to the prospect that states can make use of various forms of malware to destroy or at least erode the dependability of the command-and-control systems on which the security of states depends. Most analysts believe that applications of digital technology for offensive purposes are likely to outpace defensive applications during the foreseeable future (Perlroth 2020). This opens up the prospect of a world of states that are nominally sovereign but find their capacity to exercise power at the international level compromised and their ability to protect themselves from disruptive interventions in their internal affairs (e.g., disruptions of their electoral systems) more and more limited. These are not good developments from the perspective of the stability of international society as a society of sovereign states.

Nor is the ability of states to make use of digital technologies to manage their internal affairs without significant limitations. China's experience with the Great Firewall is interesting in this regard. There is no doubt that this effort has proven effective in restricting the access of ordinary citizens to a variety of 
materials. But as Chapter 7 makes clear, despite the scale of the resources the government has expended on the construction and reinforcement of the firewall, it is remarkable how easy it is for those with a desire to do so to get around it. Anyone with a real incentive to circumvent the restrictions of the firewall can do so with relative ease using a sophisticated VPN, taking advantage of virtual software like Zoom, and even engaging in casual interactions via WeChat. None of this is to say that the Great Firewall is ineffective or unimportant. But it does make it clear that the onset of the cyber age has complicated efforts to control the behavior of citizens, even as it has provided public authorities with new tools for exercising influence in a variety of settings.

Perhaps even more pertinent to this analysis of the future of the global order is the fact that the onset of the cyber age has opened up opportunities for new actors to engage in a variety of activities that are difficult, sometimes nearly impossible, for states to regulate effectively. Some of these activities, which may be the work of isolated individuals who are often difficult to track down effectively, are designed to reveal state secrets or disrupt the capacity of states to function effectively. The success of Wikileaks constitutes a dramatic example. But we are also witnessing a growing number of situations in which hackers break into the systems of public agencies (e.g., the Internal Revenue Service) or private corporations (e.g., hospitals and banks) in order to demand ransoms or simply to demonstrate their capacity to disrupt the ordinary flow of business. There is no question both that activities of this kind pose a large and growing challenge to public order in the cyber age and that public authorities are often behind the curve when it comes to exercising control over individuals and organizations engaging in such activities, whether their intentions are honorable or dishonorable.

It is interesting to note that the governance system dealing with uses of the internet and the world wide web has evolved over the last several decades in a self-generating fashion with little intervention on the part of states (Brousseau et al. 2012; DeNardis 2014). In contrast to efforts to address needs for governance relating to trade and the environment, there are no legally binding treaties or conventions negotiated by states in an effort to govern cyberspace. Yet, at least until recently, the governance system for the internet has worked surprisingly well and demonstrated a capacity to evolve steadily as new digital technologies have come on stream. Now, the future of this governance system seems considerably less promising. This is, fundamentally, a consequence of growing misuses of cyberspace, ranging from identity theft and bullying on the part of individual hackers to the disruption of essential services (e.g., hospitals) and the delegitimization of political institutions (e.g., election systems) on the part of those motivated to use digital technologies in an unethical fashion. It is unclear at this juncture whether it will prove possible to adapt or restructure governance systems dealing with digital technologies 
in an effective and timely manner. But one thing that does seem clear is that this is not a challenge that is likely to yield to conventional efforts on the part of states to come to terms with needs for governance through the creation of intergovernmental agreements in the form of legally binding treaties or conventions (DeNardis 2020).

\section{WHERE ON EARTH ARE WE HEADED?}

Given the analysis I have set forth in the preceding sections, what can we say about the global order of the future? This is a difficult question to answer. Without doubt, we live in a system that is tightly coupled on a planetary scale, so it certainly makes sense to cast this discussion as an effort to think about order at the global level (Testot 2020). That said, the fact that the Earth system is highly complex and becoming more so with the onset of the Anthropocene makes any effort to offer predictions regarding the evolution of the global order over time hazardous. Systems of this kind feature nonlinear changes, critical transitions, and emergent properties that make surprises a common occurrence. Still, this does not mean that we cannot engage in a disciplined assessment of the future of the global order.

Whether or not the state is obsolete, states are clearly obstinate. There is no evidence to suggest that states are prepared to eschew efforts to exercise influence beyond the boundaries of their own jurisdictions or to tolerate restrictions on their authority to deal with internal matters. Individual states may come and go. But it would be naive to expect a withering away of the state as a primary form of social organization on a global scale. Nonetheless, the impacts of the change agents I have discussed in this chapter are growing. This may be particularly important in the case of the onset of the cyber age, which is raising growing challenges to the capacity of states to exercise effective control even over activities occurring within their own borders. So, it would be shortsighted simply to accept the assumptions about the character of international society I described at the beginning of this chapter and to avoid probing enquiries into the future. So, where does this leave us in thinking about the global order of the future?

The gap between the ideal and the actual with regard to the character of international society treated as a society of sovereign states is great and may well be growing. It is true that membership in international society has almost quadrupled in the decades since the close of World War II. Some may regard this as an indicator of the robustness of international society. But the persuasiveness of this proposition is open to question. Many small states - especially the raft of micro-states - lack the capacity to function effectively as members of international society. They must rely often on the services of personnel from outside sources, such as large and well-financed nonstate actors, to 
handle routine tasks like representing themselves in intergovernmental forums. A significant number of states are experiencing civil strife or various forms of domestic turmoil that impede their ability to govern effectively within their boundaries. A number of states have become or are on the verge of becoming what we now think of as failed states. Some states - especially small island states - may become uninhabitable or literally disappear as a consequence of the impacts of climate change. Several micro-states are making plans already to relocate their entire populations to new homes located within the jurisdiction of other states in the event that sea-level rise and intensified storm surges make them uninhabitable. Even large and powerful members of international society are now finding their political systems compromised by politically motivated hacking on the part of outsiders. In short, the remarkable growth in the number of members of international society may prove quite deceptive as a measure of the robustness of the character of international society treated as a society of sovereign states.

Equally important is the growing realization that international society may not provide an effective arrangement for dealing with a range of needs for governance, such as the grand challenges of global governance in the 21st century I introduced in Chapter 2. The states system got under way in Europe during the 17th century largely as a response to a crisis regarding needs for governance that the preceding order was not capable of addressing effectively. There are good reasons to conclude that the spread of the states system beyond the boundaries of Europe is attributable in large part to the global reach of European influence, especially during the 18th and 19th centuries (Morris 2011). The process of decolonization that marked the second half of the 20th century is widely interpreted as a measure of the decline of European domination of a global scale. But it is worth emphasizing that the flood of new states emerging in the wake of decolonization has resulted in the globalization of what is essentially a European invention. The fact that this institutional construct does not fit the circumstances prevailing in some parts of the world comfortably is one source of the large gap between the ideal and the actual documented earlier in this chapter.

When it comes to addressing the grand challenges of the 21 st century, there are growing doubts about the efficacy of the states system. Starting with the signing of the UN Framework Convention on Climate Change (UNFCCC) in 1992, we have sought to come to terms with the problem of climate change using the standard practices associated with international society. But the results unfolding over the last 30 years have been unimpressive; we are far from a solution to this problem, even under the terms of the 2015 Paris Climate Agreement. Any real solution will require fundamental changes in the socioeconomic systems prevailing within states, a transition that is difficult to achieve through the provisions of intergovernmental agreements. We have 
not even begun to tackle the other grand challenges through efforts making use of the standard practices of international society. The Covid-19 pandemic provides dramatic evidence of the failure of international governance; there is every reason to expect new infectious diseases to arise and spread globally during the foreseeable future. Disruptive misuses of cyberspace are spreading rapidly and becoming increasingly severe. States are hard pressed to cope with digital interventions in their internal affairs; they have not begun to engage in the hard work of devising effective international governance mechanisms to address this problem. The revolution in biotechnology is producing a cascade of innovations that we are only beginning to understand, much less to respond to effectively from the perspective of governance. It is doubtful whether states will be able to control the action in this realm, even if they come to recognize the scope of this emerging challenge.

So, we may find ourselves facing governance challenges in the 21 st century on a scale that rivals the challenges that European leaders struggled to deal with during the first half of the 17th century. But recognizing these challenges is one thing; doing something about them is another. A striking observation in this regard is that significant innovations would require major shifts in entrenched social practices embedded in the constitutive institutional arrangements of international society. The efforts of states seeking to solve problems by negotiating international legally binding instruments may be inadequate to come to terms with the grand challenges of global governance in the 21st century. But only entities that meet the qualifications for acceptance as states are eligible to become members of international society and to participate in such efforts. The negotiation of international treaties or conventions constitutes the principal means of addressing problems of governance in international society. Only states are qualified to become members of intergovernmental organizations, ranging from formal global bodies like the United Nations to informal regional forums like the Arctic Council. With a few exceptions, states are the entities authorized to initiate litigation in international courts and tribunals (Squatrito et al. 2018). In the case of the International Court of Justice, states cannot be made to appear as defendants in legal actions initiated by others in the absence of their consent. We can point to inroads on some of these institutional principles at the margins. Nevertheless, it is hard to find convincing evidence that the institutional foundations of international society are on the verge of collapse.

How might this situation change, and what might the consequences be for the global order of the future in the event that we do begin to witness significant shifts in the constitutive institutions that define the character of international society? The first thing to note in thinking about this question is that social institutions are not facts of life. They are human constructs that reflect the character of the societies in which they operate. That is why it would be foolish to expect congruence between the governance systems of modern 
nation states and those of traditional Indigenous societies or to assume that different societies will converge toward a common system of public order over time. Social institutions are often sticky; they can linger on for more or less protracted periods, even when the societal conditions that gave rise to them have shifted profoundly. Without adopting extreme views like those of Spengler, who imagined obsolete but frozen systems lasting for centuries (Spengler 1991), we can acknowledge that inertia is a powerful force leading to the survival of institutions even when they no longer reflect underlying societal conditions. At the same time, institutions do change. In some cases, shifts in the deep structure of existing orders occur over relatively long periods of time in ways that are little noticed or poorly understood prior to the eruption of crises in which the gathering forces of change coalesce to trigger dramatic developments whose significance is apparent to all informed observers.

Is this observation relevant to the case of international society during the current era? In responding to this question, it is pertinent to emphasize that in the Anthropocene, in contrast to the Holocene, we are operating in a system characterized by increasing complexity on a planetary scale. The contrast between the remarkable stability of the Earth's climate system during the Holocene and the increasing volatility of the climate system today is a striking example of growing complexity. But similar developments are beginning to surface in a variety of spheres. Those who work on issues relating to complex systems draw a distinction between bifurcations or critical transitions from one system to another and oscillations or cyclical changes occurring within the same system (Scheffer 2009). In thinking about the occurrence of bifurcations, they draw attention to what are known as tipping elements along with thresholds and triggers. The challenge is not only to identify thresholds and triggers, but also to explain or predict when triggers will activate tipping elements leading (sometimes suddenly) to critical transitions from one system to another or from one state of a system (e.g., the Earth system) to another fundamentally different state. As the case of climate change makes clear, it is difficult to foresee, much less to predict precisely, when bifurcations will occur in complex systems. We know that there are major tipping elements in the climate system, and we know that volatility is on the rise in this system (Lenton et al. 2008). It is perfectly possible that the climate system will experience a bifurcation in the relatively near future. But no one is in a position to predict confidently if or precisely when such a critical transition will occur.

Similar observations apply to human systems, including international society. At the macro level, we can point to critical transitions, such as the collapse of the Roman Empire leading to a much more fragmented system, the emergence of a states system initially in Europe in the wake of the Treaty of Westphalia in 1648, and the Industrial Revolution initiating the rise of modern capitalism starting in the second half of the 18th century. Bifurcations occur 
more frequently at the meso level or the level of individual societies. The collapse of the Ancien Régime in France toward the close of the 18th century is a prominent example. So is the unification of Germany and Italy as modern states in the 19th century, the founding of the Soviet Union in 1922, and the subsequent collapse of the Soviet Union at the end of 1991. These examples highlight the facts that unstable systems can linger on for relatively long periods of time, that trigger mechanisms can strike sparks leading to crises catalyzing critical transitions that seem to occur suddenly, and that we are regularly taken by surprise by these transformative events, even when we are aware of the existence of tipping elements in prevailing systems. The relevance of these observations to the future of the global order is straightforward. There are certainly tipping elements in international society; it is not difficult to identify pathways that could lead to a critical transition in which the prevailing system gives way to some fundamentally different successor, perhaps even over a relatively short period of time. But there is no way to go beyond subjective calculations of probabilities in seeking to determine if and when we are likely to experience a critical transition with regard to the character of the global order.

There remains the question of what form an alternative global order might take. In my judgment, there is little prospect that a new global order would be hierarchical in the sense that it would include some entity we could think of as a global or world government possessing both the authority and the capacity to make and implement binding decisions regarding the activities of the members of a new global society. Of course, it is interesting to speculate about options featuring a loose confederation in which the powers allocated to a global public authority would be sharply restricted relative to the powers retained by its constituents. But even a loose confederation at the global level seems improbable. The entities capable of operating as independent actors in world affairs are so diverse on many levels that it is hard to imagine the rise of some sort of liberalism or "solidarism" on a global scale (Hurrell 2007). If anything, diversity in these terms is rising rather than declining today. There is no indication that we will witness what some have described as "the end of history" or the rise of some sort of global community during the foreseeable future (Fukuyama 1992; Keene 2002).

An issue of considerable interest in this realm centers on the question of whether a new global order would be homogeneous with regard to the character of its members. In other words, just as all the members of international society today are entities recognized as states, would all the members of a new order be similar in terms of some defining attributes? Or can we imagine a global order encompassing a mix of different types of actors that are not subordinate to one another in any legal or political sense? Those of us who grew up taking the defining features of international society for granted may 
be tempted to assume that there are always powerful forces pushing systems toward homogenization with regard to the character of their members. But it is doubtful whether this assumption can withstand careful scrutiny. Systems featuring considerable heterogeneity with regard to the character of their members prevailed over long periods of time in Europe prior to the middle of the 17th century and in Asia during the long ascendancy of China as the Middle Kingdom. This suggests we should guard against the adoption of simple assumptions regarding the homogeneity of the actors in systems of public order reflecting nothing more than the fact that we have grown up in international society treated as a social system in which all the members are sovereign states.

In the end, there is much to be said for engaging in systematic thinking about the future of the global order, even though we cannot expect to make accurate predictions regarding what form the global order of the future may take. Bifurcations can occur with remarkable speed in complex systems, and the cost of being unprepared to deal with a new order once a critical transition occurs is likely to be high. Mainstream analyses of oscillations within international society are not useless. It is helpful to think about topics like the decline of the American world order or the dynamics of unipolar, bipolar, and multipolar systems. But these analyses do little to build the intellectual capital we will need to operate successfully in a global order that differs fundamentally from the international society of recent times. It is time to turn our attention in a rigorous yet imaginative way to enhancing our understanding of the dynamics of alternative forms of order that may arise on a global scale during the coming decades. 